\title{
Management of malignant tumors of the anterior skull base: experience with 76 patients
}

\author{
Ketan R. Bulsara, M.D., TaKanori Fukushima, M.D., D.M.Sc., AND \\ Allan H. Friedman, M.D. \\ Duke Division of Neurosurgery, Durham; and Carolina Neuroscience Institute, Raleigh, North \\ Carolina
}

\begin{abstract}
As the management of anterior cranial fossa malignancies has undergone significant evolution, decreases in morbidity and mortality rates have occurred. In this article, the authors discuss the clinical presentation, neuroimaging findings, and management options for common anterior skull base malignancies. Also discussed are surgery-related indications and principles.
\end{abstract}

\section{KEY WORDS • anterior skull base • esthesioneuroblastoma • transfacial}

\author{
transbasal • nasopharyngeal carcinoma •
}

In 1941 Dandy described anterior craniofacial resection of orbital tumors. ${ }^{20}$ Prior to this, Frazier ${ }^{27}$ championed re- $^{-}$ moving orbital rims to gain improved surgical access. In 1943 Ray and McLean ${ }^{59}$ combined a transcranial and transfacial approach for resection of a retinoblastoma. The first en bloc resection of an extensive paranasal sinus malignancy was initially reported by Smith, et al., ${ }^{71}$ in 1954 and subsequently by Ketcham, et al., ${ }^{38}$ and Van Buren, et al. ${ }^{79}$ Although complete tumor resection had considerable benefits, the toll was an $80 \%$ morbidity rate and a $7 \%$ mortality rate. ${ }^{38,69}$ The major cause of morbidity was intracranial contamination due to sinonasal tract communication. ${ }^{64}$ This complication was reduced when reconstructive techniques involving pericranial grafts were introduced in 1979 by Schramm, et al., ${ }^{65}$ and modified later by Johns, et al. ${ }^{37}$ With improvements in surgical techniques, the morbidity rate decreased to less than $40 \%$ and mortality to between 0 to $2 \% .45,46$

In 1960 Tessier, et al., ${ }^{76}$ pioneered the transbasal approach for the reduction of craniofacial abnormalities. Derome, alone, ${ }^{21}$ with Tessier, ${ }^{22}$ and with others ${ }^{23}$ used this approach for sphenoethmoidal tumor removal beginning in the 1970s. Modifications of this approach have led to increased anterior cranial fossa exposure requiring minimal brain retraction.

\footnotetext{
Abbreviations used in this paper: $\mathrm{CA}=$ carotid artery; $\mathrm{CSF}=$ cerebrospinal fluid; $\mathrm{CT}=$ computerized tomography; $\mathrm{ICA}=$ internal $\mathrm{CA} ; \mathrm{MR}=$ magnetic resonance; $\mathrm{UCNT}=$ undifferentiated carcinoma of the nasopharyngeal type; $\mathrm{WHO}=$ World Health Organization.
}

Anterior transfacial approaches were described as early as 1829 by Lizars. Modifications were described by Fergusson in $1842 .{ }^{9}$ In the 1920 s, Portmann and Retrouvey reported the midfacial degloving procedure. ${ }^{7}$ Casson and associates $^{10}$ further modified this technique, which was then popularized by Conley and Price ${ }^{16}$ and Price alone. ${ }^{55}$ A subcranial approach obviating the need for the transfacial approach was initially described by Raveh, et al., ${ }^{58}$ in 1978 for the management of craniofacial fractures and subsequently performed for the management of anterior skull base tumors.

The management of malignant tumors of the anterior skull base can be technically demanding and has been associated with high rates of morbidity and mortality. Advances in neuroimaging leading to earlier diagnosis, a better understanding of the anatomy, and collaboration among experienced surgeons has led to significant progress in the management of these lesions.

\section{MANAGEMENT OF ANTERIOR SKULL BASE MALIGANCIES}

\section{Presentation and Neuroimaging Features}

Anterior fossa tumors can manifest as a number of different symptoms, including nasal obstruction and congestion, epistaxis, rhinorrhea, hyposmia or anosmia, headache, seizure, and psychological changes. Paresthesias in the distribution of the V1 or V2 divisions of the trigeminal nerve may occur. Invasion into the sella turcica can cause loss of endocrine function, or invasive pituitary tu- 
mors can be responsible for over production of corticosteroids, growth hormone, or prolactin. Visual loss can be uni- or bilateral. Associated ocular symptoms include diplopia, orbital pain, exophthalmos, and retroorbital headaches. Many of these tumors can be demonstrated on nasopharyngeal examination.

Diverse tumors can involve the anterior cranial fossa. Primary benign tumors with rare malignant potential include meningiomas and pituitary adenomas. Primary malignant tumors include chordomas, chondrosarcomas, osteogenic sarcomas, and invasive pituitary tumors. Malignant tumors with secondary involvement include carcinoma of the paranasal sinuses. Others include lymphoma arising from the adenoids, minor salivary gland neoplasms, ethmoid carcinoma, paragangliomas, olfactory neuroblastomas, mucoepidermoid carcinomas, and osteosarcomas. Histologically benign tumors include angiofibromas and inverted papillomas. Metastases from renal, breast, and lung carcinoma can also involve the anterior cranial fossa. Teratocarcinomas are rare in this region (Fig. 1). Lastly, paranasal sinus infections can extend into the anterior skull base.

Computerized tomography and MR imaging provide complementary information regarding skull base lesions. Whereas CT scanning is better at defining osseous anatomy and calcifications, MR imaging is superior at demonstrating the relationship of skull base masses to soft-tissue structures such as cranial nerves, the CA, the jugular vein, and the brain. In the case of parasellar masses, MR imaging is better in excluding CA aneurysms.

Nasopharyngeal Carcinoma. Nasopharyngeal carcinoma arises from the surface epithelium of the nasopharynx and commonly metastasizes to the lymph nodes, with some preference for those at the apex of the posterior cervical triangle. ${ }^{18}$ As many as $82 \%$ of the tumors arise in the lateral wall of the nasopharynx in Rosenmüller fossa (pharyngeal recess), $12 \%$ in the midline, and $6 \%$ in normalappearing mucosa. ${ }^{70}$

Nasopharyngeal carcinoma has a bimodal age distribu-

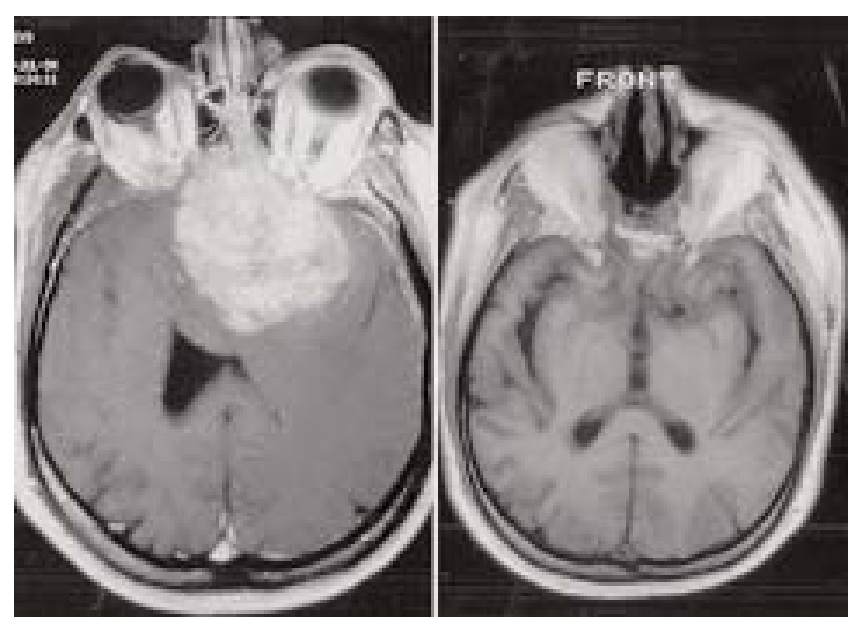

Fig. 1. Neuroimaging studies. Left: Pathological diagnosis of this heterogeneously enhancing lesion was teratocarcinoma. Right: Two years following an extensive transbasal resection, no tumor recurrence is noted. tion with peaks in the second and sixth decades of life. It occurs predominantly in males. It is divided into two distinct histological entities: squamous cell carcinoma and UCNT. The WHO classifies nasopharyngeal carcinoma based on the degree of differentiation: ${ }^{67,70,81}$ Type I is a keratinizing squamous cell carcinoma similar to that found in the rest of the upper digestive tract; Type II is a nonkeratinizing epidermoid carcinoma; and Type III is UCNT. Numerous staging schemes are present for maxillary and ethmoid neoplasms; however, only the University of Florida staging system can be applied to all paranasal neoplasms..$^{50,52}$ In this classification system, T1 tumors are limited to a single site of origin such as a nasal wall or ethmoids; T2 tumors extend to an adjacent sinus, orbit, palate, nasopharynx, or pterygomaxillary sites; and T3 tumors extend to or through the skull base. Resection of T1 tumors is associated with the least morbidity and mortality

The UCNT differs from other head and neck squamous cell carcinomas by its histological features, epidemiological characteristics, and its relation with the Epstein-Barr virus. Of nasopharyngeal carcinomas, it is the more prevalent. It is endemic in Southeast Asia, parts of the Mediterranean basin, North Africa, parts of the Caribbean and Alaska. A characteristic feature of the undifferentiated tumor is massive lymphoid T-cell infiltration.

The UCNT is associated with the Epstein-Barr virus. ${ }^{35,75,78,80}$ Deletion of tumor suppressor genes such as $p 16$ or the activation of oncogenes such as $b c l-2$ may predispose individuals to the development of WHO Types II and III carcinoma. ${ }^{47,48}$ Dietary factors such as salted fish high in volatile nitrosamines have also been implicated in $\mathrm{UCNT}^{82}$

Squamous cell carcinoma (WHO Type I) is more common in the Western population. The use of tobacco and alcohol may play a role in the development of this welldifferentiated tumor. ${ }^{13}$ It is rarely associated with the Epstein-Barr virus. Mutations of the p53 gene commonly occur. ${ }^{26}$

Patients with nasopharyngeal carcinoma may present with variable nonspecific symptoms, the most common of which is painless posterior cervical adenopathy. Lateral pharyngeal node involvement may result in pain with ipsilateral neck rotation or ear pain. Unilateral conductive hearing loss resulting from serous effusions due to poor eustachian tube function commonly occurs. Nasal obstruction occurs late in the course of the disease and profuse epistaxis is rare. Dysphonia, difficulty swallowing, and diplopia may also occur. Physical examination may reveal maxillary nerve dysfunction. Extension of the tumor into the lateral pharynx results in ninth and 10th cranial nerve palsies. Proptosis and trismus are rarely associated with these malignancies.

Nasopharyngeal carcinoma is associated with bone destruction demonstrated on CT scanning. Intense homogeneous enhancement of the lesion is seen following contrast administration. The lesion can invade the middle fossa either by erosion through the greater wing of the sphenoid or extension through the foramen ovale. In advanced cases, the cancer can reach the clivus and violate areas of the posterior fossa. Adenoid cystic carcinomas are also associated with bone destruction. Postcontrast 
MR imaging may reveal perineural spread of the malignancy particularly along the V2 and V3 distribution.

The treatment of choice for nasopharyngeal carcinoma is chemotherapy followed by radiotherapy, although some authors have advocated surgery followed by radiotherapy. ${ }^{24}$ The histological type clearly affects outcome. Patients with squamous cell carcinoma fare worse than those with WHO Type II or III carcinoma in terms of local disease control and overall survival. The Type II and III carcinomas are more radio- and chemosensitive compared with the keratinizing squamous cell carcinoma. Despite improvements in management of nasopharyngeal carcinomas, the rate of cancer-free survival at 5 years is less than $50 \%$ for all stages. ${ }^{24}$ It is 25 to $30 \%$ for advanced stages of disease.

Although early results suggest that chemotherapy may be beneficial, the data are limited. ${ }^{24}$ Providing concomitant radio- and chemotherapy with cisplatin, Choi, et al., ${ }^{12}$ reported 5-year survival rates in $50 \%$ of their patients with advanced disease. Induction chemoradiotherapy with 5fluorouracil and cisplatin may lead to improved survival rates. Intraarterial chemotherapy has recently been applied in cases of paranasal sinus cancers supplied by the internal maxillary artery. ${ }^{24,43,44}$ Selective delivery of agents such as cisplatin by this technique increases tumor-drug concentration. $^{15}$

Olfactory Neuroblastoma (Esthesioneuroblastoma). Olfactory neuroblastomas, also known as esthesioneuroblastomas, are rare tumors arising from olfactory mucosa of the cribriform plate, superior turbinates, and the upper third of the nasal septum. They present most commonly with intractable nasal blockage or epistaxis, less commonly with local headache, rhinorrhea, visual disturbances, or anosmia, and rarely with proptosis, cheek swelling, or a neck mass. Modified Kadish system tumor staging provides the following classifications: Stage A, confined to nasal cavity; $\mathrm{B}$, involving area around paranasal sinus; $\mathrm{C}$, extension in the orbit, skull base, or cranium; and D, distant metastases. ${ }^{1}$ Cervical metastases occur in fewer than $10 \%$ of Stage A and B cases but are present in $44 \%$ of Stage $\mathrm{C}$ cases.

Evaluation should include CT evaluation to evaluate osseous erosion of the skull base as well as MR imaging to differentiate tumor from sinus obstruction in the paranasal sinuses (Figs. 2 and 3). Gadolinium enhancement is used to evaluate tumor erosion through the cribriform plate and metastases to cervical lymph nodes. The differential diagnosis for olfactory neuroblastoma includes melanoma, lymphoma, extramedullary plasmacytoma, rhabdomyosarcoma, and sinonasal undifferentiated carcinoma.

At present there is no proven optimal therapy for esthesioneuroblastoma, but a consensus does seem to be emerging in the literature. Lesions confined to the nasal cavity, free from the cribriform plate, and with tumor-free margins can be treated by surgery alone via an extracranial approach. Anterior craniofacial surgery is performed in the majority of cases involving the cribriform plate. The extracranial dissection can be performed transnasally, endoscopically, or through a lateral rhinotomy. Intracranial surgery can be approached through a bifrontal craniotomy or through large frontal sinuses, taking advantage of a frontal sinus template prepared prior to surgery.
Radiotherapy is recommended for low-grade tumors without clean surgical margins and all high-grade tumors. Most radiotherapists recommend administering a 50 to 60-Gy dose of radiation postoperatively. At some institutions a 50-Gy dose is administered preoperatively to shrink large irregular tumors. ${ }^{54}$ Formulating a treatment plan for radiotherapy is difficult because of the irregular shape of the tumor and the adjacent radiosensitive optic nerves, pituitary gland, and frontal lobes.

The most commonly used chemotherapy regimen includes cyclophosphamide and vincristine. ${ }^{24,68}$ Electron microscopy shows neurosecretory granules, and immunohistochemistry is positive for S100 protein and neuronspecific enolase and negative for epithelial and lymphoma markers. ${ }^{61}$ The absence of rosettes, increased mitotic activity, necrosis, and nuclear pleomorphism in olfactory neuroblastoma correlate with a poor prognosis.

Rhabdomyosarcoma. Rhabdomyosarcomas of the head and neck were first reported in 1854 by Weber and not histologically classified until $1947 .^{49,74}$ These tumors occur predominantly in the pediatric population. Children younger than age 5 years harbor the aggressive embryonal variant and older patients the pleomorphic variant. Approximately $40 \%$ of patients have head and neck involvement, which can be orbital, nonparameningeal/nonorbital, and parameningeal. ${ }^{52}$

Magnetic resonance imaging reveals a soft-tissue mass in the sinonasal region, infratemporal fossa, or nasopharynx with significant contrast enhancement. Computerized tomography scanning commonly demonstrates bone destruction. Five-year survival rates of $94 \%$ in cases of orbital tumors and $50 \%$ in cases involving other head and neck regions were reported in $1983 .{ }^{40}$

In recent years, improved outcomes have been associated with early provision of chemoradiation therapy and resection. ${ }^{52}$ Radiotherapy in 150 - to 200 -cGy fractions is commonly undertaken for a total dose of 4140 to 6500 cGy. Radiotherapy is primarily responsible for the neuroendocrine, dental, and thyroid sequelae. It partially contributes to visual loss and facial asymmetry. Investigators in the Intergroup Rhabdomyosarcoma Studies II and III

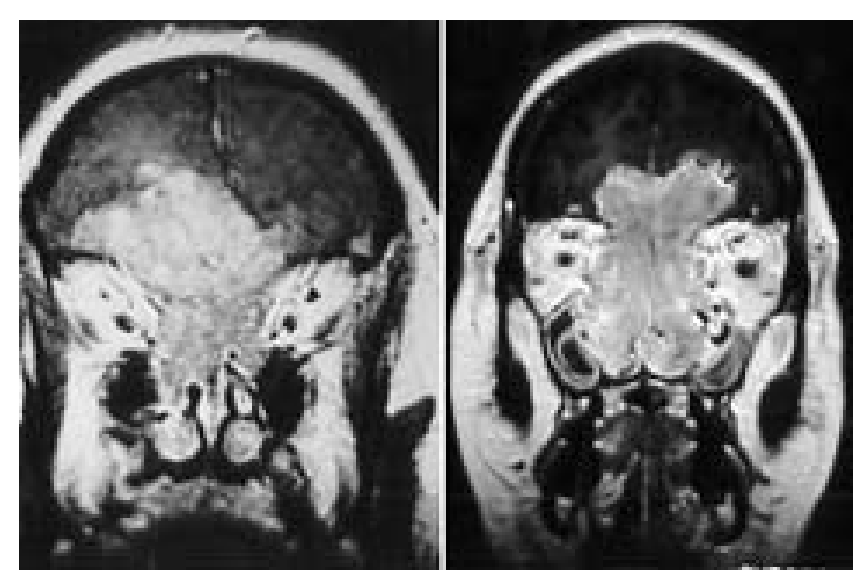

Fig. 2. Neuroimaging studies. Left and Right: Representative images of invasive esthesioneuroblastoma. Even with aggressive management, it is often difficult to achieve a 2-year survival rate in these cases. 


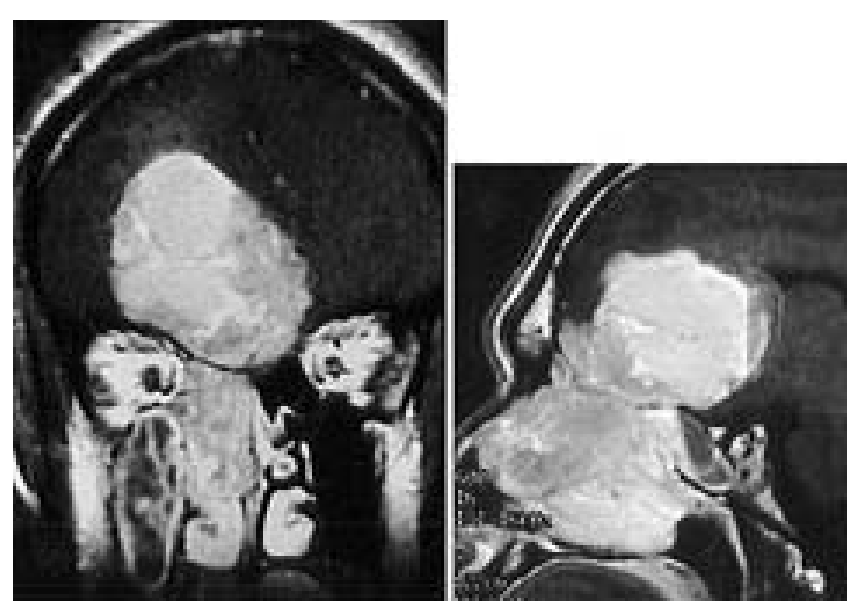

Fig. 3. Neuroimaging studies.The invasive nature of esthesioneuroblastoma precludes long-term survival in advanced cases. Left and Right: In this rare exception, a 10-year malignancy-free survival rate was noted postoperatively.

have demonstrated that at least $77 \%$ of children develop one problem within 7 years following their treatment regimen. ${ }^{57}$ Long-term follow-up data in these patients are needed because the late effects of radiotherapy can occur up to 10 years posttreatment..$^{52}$

Recurrences when resection is not performed are common. Rhabdomyosarcomas have a propensity to metastasize prior to operative intervention. Pulmonary metastases are associated with the worst prognosis.

Chordomas and Chondrosarcomas. Chordomas were described as early as 1856 by Lusckha ${ }^{66}$ They are malignant neoplasms arising from remnants of the embryonic notochord. Chordomas and chondrosarcomas, which account for fewer than $1 \%$ of intracranial tumors, are pathologically distinct. These tumors have a propensity to occur in the third to fifth decades of life. ${ }^{66}$

Chordomas and chondrosarcomas invade locally (Fig. 4). Although relatively rare, metastases of intracranial chordomas to the lymph nodes, lungs, liver, bone, skin, and muscles have been reported. ${ }^{11}$ The conventional chordoma has vacuolated mucus containing physaliphorous cells. The chondroid type has cartilaginous tissue and is associated with a better prognosis. ${ }^{17,29,34,56,60,63,73}$ Some authors have argued these are immunohistochemically lowgrade chondrosarcomas. ${ }^{5,6}$

Chondrosarcomas are classified as classic, mesenchymal, or dedifferentiated. ${ }^{19}$ The classic variant has large multinucleated cells with abundant cartilage. This group is further divided into Grades I to III based on mitoses, nuclear size, and extent of cartilage matrix. The mesenchymal variant has islands of undifferentiated mesenchymal cells and cartilage. These are more aggressive tumors. They commonly occur at the petrosphenoclival junction. The dedifferentiated variant is similar to anaplastic sarcoma. Immunohistochemical markers can differentiate chordomas and chondrosarcomas. The former do not stain for epithelial markers or oncofetal antigens.

The most common presenting symptoms include orbitofrontal headaches, visual disturbances, and ophthalmoplegia. Trigeminal, facial, and vestibulocochlear neu-

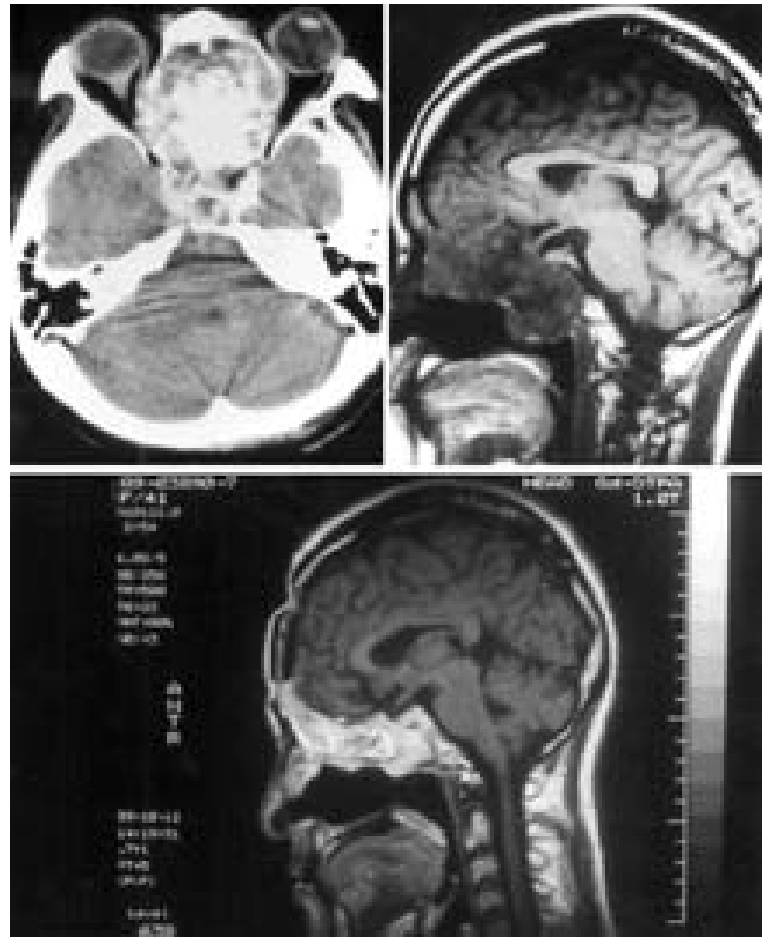

Fig. 4. Neuroimaging studies. Upper Left and Right: Chondrosarcomas can invade locally. Lower: Following an extensive transbasal approach for resection and postoperative radiotherapy, a 6-year survival rate without significant recurrence was demonstrated.

ropathies may also be present because of extension of the tumor into the cerebellopontine angle and internal auditory meatus. Computerized tomography scanning reveals bone destruction without sclerosis. Magnetic resonance imaging reveals hypointense or isointense lesions on $\mathrm{T}_{1}$ weighted sequences that enhance brightly with gadolinium. Cystic areas of hemorrhage or mucoid material may be present. These are bright on $\mathrm{T}_{2}$-weighted sequences.

In patients with chondrosarcomas who undergo surgery and proton-beam radiotherapy 5- and 10-year survival rates of 99 and $98 \%$, respectively, have been reported. ${ }^{62}$ Chordomas are associated with a less favorable prognosis, their 5- and 10-year survival rates being 51 and 35\%, respectively. The five-year recurrence-free survival rate following gross-total resection and proton-beam radiotherapy is $100 \%$ for chondrosarcomas and $51.6 \%$ for chordomas. ${ }^{14}$

Chordomas and chondrosarcomas are resistant to conventional doses of radiotherapy in the range of 50 to 70 Gy. ${ }^{66}$ They are radiosensitive to doses as high as $80 \mathrm{~Gy}$. Considerable injury to adjacent critical neurovascular structures and radiation-induced necrosis are the major morbidities. Proton-beam radiotherapy with dose ranges of 50- to 75-cobalt Gy equivalents, has been administered as an adjunctive therapy to microsurgical resection to improve outcomes. ${ }^{2,4,66}$ This treatment modality has a $34 \%$ complication rate. ${ }^{66}$ Endocrine, auditory, seizures, and radionecrosis complications occur. No chemotherapy regimen has proven consistently effective. Chemotherapy is 
used as a last resort in patients in whom both surgery and radiotherapy have failed.

The consensus emerging from the literature is that resection followed by proton-beam radiotherapy for residual tumor is the most effective therapeutic paradigm. ${ }^{66}$ Total or near-total resection of these tumors by experienced surgeons does not increase the risk of postoperative cranial nerve deficits. ${ }^{40}$

Malignant Meningiomas. Meningiomas of the anterior cranial fossa skull can be typical benign tumors, atypical tumors prone to recurrence, or rare lesions that are overly malignant or anaplastic. ${ }^{8}$ Three percent of all intracranial meningiomas secondarily involve the sinonasal tract. ${ }^{53,61}$ Tumor extension can also lead to involvement of the orbit and parapharyngeal space. ${ }^{3}$ Predisposing factors for the development of meningiomas include female sex, previous radiotherapy, and neurofibromatosis Type 2 .

Atypical meningiomas do not have frank anaplasia. They demonstrate hypercellularity, patternless growth, focal necrosis, high nucleus-cytoplasm ratios, coarse chromatin, and prominent nucleoli. Numerous tumor cells undergoing mitosis are also commonly seen. Increased mitotic activity in this group of tumors is defined as four or more mitoses per $10 \mathrm{hpf} .^{41}$ Aneuploidy and high proliferation index based on bromodeoxyuridine studies correlate with a higher rate of local recurrence. ${ }^{8}$

Malignant meningiomas, by definition, have unequivocal anaplasia and/or invasion of brain parenchyma. Neuroimaging demonstrates an inordinate amount of edema and lack of a smooth contoured tumor-brain interface. Cytologically, the malignant areas range from a meningothelial appearance to a vaguely epithelial or sarcomatous appearance. The meningiomatous nature of the anaplastic tumor may be difficult to appreciate initially. Twenty or more mitoses per $10 \mathrm{hpf}$ are present. The most common sites of metastasis are liver, lungs, pleura, and lymph nodes. ${ }^{33}$ Increased labeling with bromodeoxyuridine and monoclonal antibody Ki-67 occur in cases of aggressive tumors. ${ }^{33}$ Meningiomas are positive for epithelial membrane antigen and vimentin, and negative for anti-Leu 7 and glial fibrillary acidic protein. In patients with malignant meningiomas median survival is less than 2 years. $^{41}$

The three common histological patterns of typical meningiomas are syncytial, fibroblastic, and transitional. The syncytial growth pattern is the most common. Histological patterns have no prognostic significance. ${ }^{61}$ The most common chromosomal abnormality is loss of chromosome 22 q 12.3-q ter. ${ }^{3,33}$ In meningiomas with an aggressive or invasive course and frequent recurrences deletion of the short arm of chromosome 1 is also present. ${ }^{39}$

Curative therapy for meningiomas is complete resection. Radiotherapy is reserved for application in patients in whom incomplete tumor resections have been performed because of the risk of injury to critical neurovascular structures; in those with malignant meningiomas; or in rare cases in which the tumor may be judged inoperable. A large number of nonmalignant meningiomas have hormonal receptors. Pharmacotherapy aimed at these hormonal receptors includes bromocriptine, mifepristone, and RU486. ${ }^{33}$ Although there was initial enthusiasm for antiprogesterones, its administration in patients with un- resectable meningiomas has not been encouraging. ${ }^{30-32}$ Trapidil has known antagonistic action on platelet-derived growth factor and has been shown to exhibit some inhibition of meningioma cell proliferation. ${ }^{77,80}$

\section{SURGICAL APPROACHES Surgery-Related Anatomy}

The anterior cranial fossa is bound anteriorly by the frontal bone, inferiorly by the orbital roofs, the greater wing of the sphenoid posterior laterally, and the lesser sphenoid wings posterior medially ${ }^{42}$ (Fig. 5). The foramen cecum is in the midline behind the frontal bone, its posterior and lateral boundaries formed by the ethmoid bone. The crista galli is an osseous ridge arising from the midline of the ethmoid bone. The cribriform plate which is on either side of the crista, contains the olfactory foramina through which the anterior and posterior ethmoidal arteries and olfactory nerves travel. The planum sphenoidale and the lesser wing of the sphenoid constitute the posterior floor of the anterior cranial fossa behind the cribriform plate.

The dura mater over the cribriform plates is thin. The blood supply to the anterior cranial fossa is from the anterior and posterior ethmoidal, middle meningeal, and ICA via the ophthalmic artery. The medial portion of the anterior cranial fossa contains the pneumatized frontal, ethmoidal, and sphenoid sinuses.

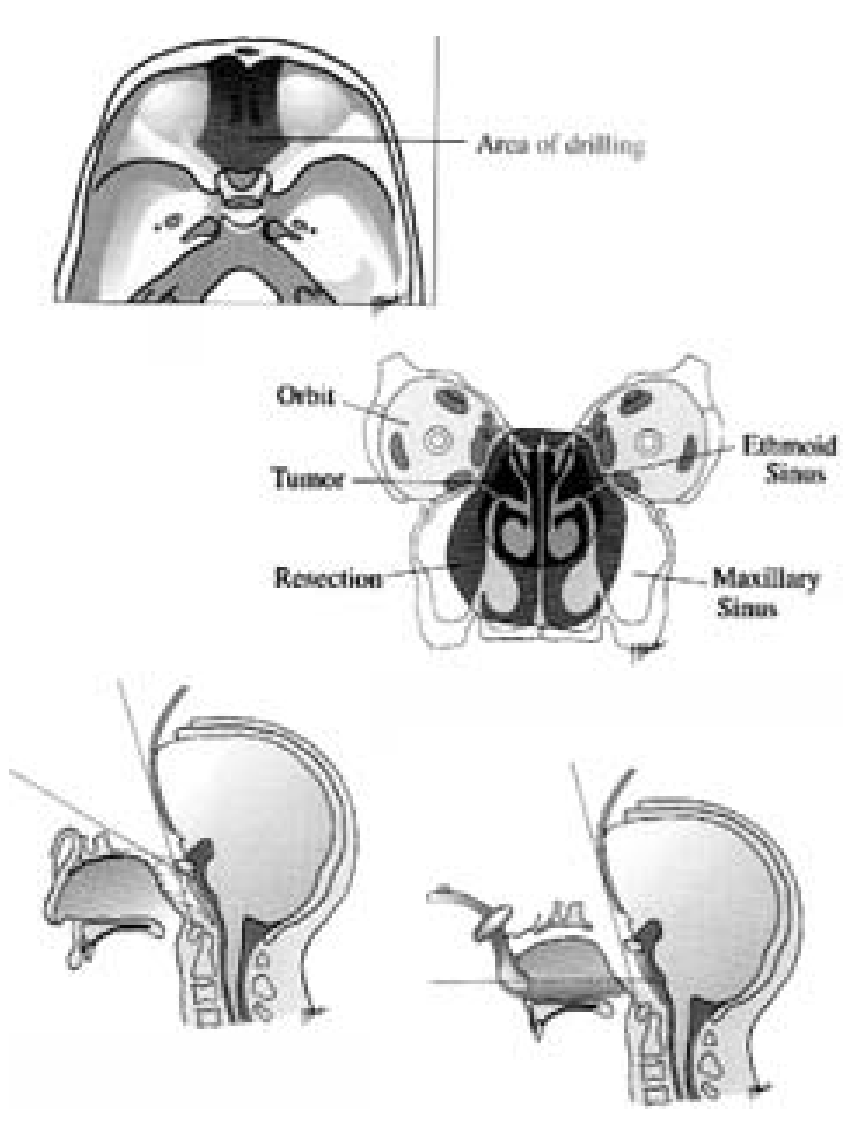

Fig. 5. Drawings providing an overview of the anterior cranial fossa anatomy and the surgical approaches. 
The roof of the orbit is formed by the orbital process of the frontal bone, whereas the greater and lesser wings of the sphenoid form the apex and lateral wall of the orbits. The zygomatic bone marks its lateral wall. The lacrimal, ethmoid, palantine, and sphenoid bones comprise the medial wall of the orbit. The pterygoid plate lies beneath the greater wing of the sphenoid. The foramen rotundum and the inferior orbital fissure lie at the anterior end of the pterygoid plates. At the posterior end lies the foramen ovale.

The ethmoidal foramina are situated at the level of the frontoethmoidal suture. These foramina transmit the ethmoidal arteries and nerves. The posterior ethmoidal foramen is approximately $5 \mathrm{~mm}$ anterior to the orbital opening of the optic canal. The optic foramen lies at the posterior limit of the anterior cranial base.

\section{Indications for Surgery and Surgery-Related Principles}

Our indications for surgery and its principles are based on the experience of the senior author (T.F.) with 76 cases of malignant tumors of the anterior skull base. Lesions in this series were giant pituitary carcinomas (two cases), malignant craniopharyngioma (one), malignant meningioma (six), teratocarcinoma (one), esthesioneuroblastoma (13), plasmacytoma (two), hemangiopericytoma (four), ethmoid small cell carcinoma (four), rhabdomyosarcoma (two), liposarcoma (one), basal cell carcinoma (one), malignant ameloblastoma (two), lacrimal gland carcinoma (one), squamous cell carcinoma (10), adenoid cystic carcinoma (four), chondrosarcoma (four), chordoma of the upper clivus (12), giant cell tumor (two), and adenocarcinoma (four cases).

In our experience, surgery should be reserved for cases in which at least 2 to 5 years of useful life remain following aggressive resection. Bilateral cavernous sinus involvement is a contraindication to surgery. To ensure patient longevity cranial nerve sacrifice, orbitectomy, eye exoneration, unilateral cavernous sinus sacrifice, or CA bypass may be necessary. These are only justified if they lead to complete en bloc tumor resection.

Surgical approaches to the anterior cranial fossa can be divided into five categories: 1) unilateral frontal transbasal; 2) bilateral transbasal; 3) extended bifrontal transbasal; 4) combined transbasal transcavernous; and 5) transfacial-transbasal. The basic principle underlying each approach is en bloc resection of the tumor. A goal of a tumor-free margin of $1 \mathrm{~cm}$ is attempted. Because of the propensity for spread of malignant cells, quick debulking is needed. The use of suction systems such as the Fukushima suction retractor help prevent spread of malignant cells. The drill is used minimally with a surgical osteotome preferred for most bone work.

Preoperative and postoperative radiotherapy in cases involving radiosensitive tumors such as esthesioneuroblastoma and ethmoid cell cancer (Fig. 6) is performed prior to radical resections.

Unilateral and Bilateral Transbasal Approach. The unilateral and bilateral transbasal approaches begin with a bicoronal skin incision, uni- or bifrontal craniotomy, opening of the frontal sinuses, and a subfrontal extradural approach to lesions. Whereas a unilateral approach may suffice for lateral anterior fossa lesions, middle anterior fossa lesions require a bifrontal approach.

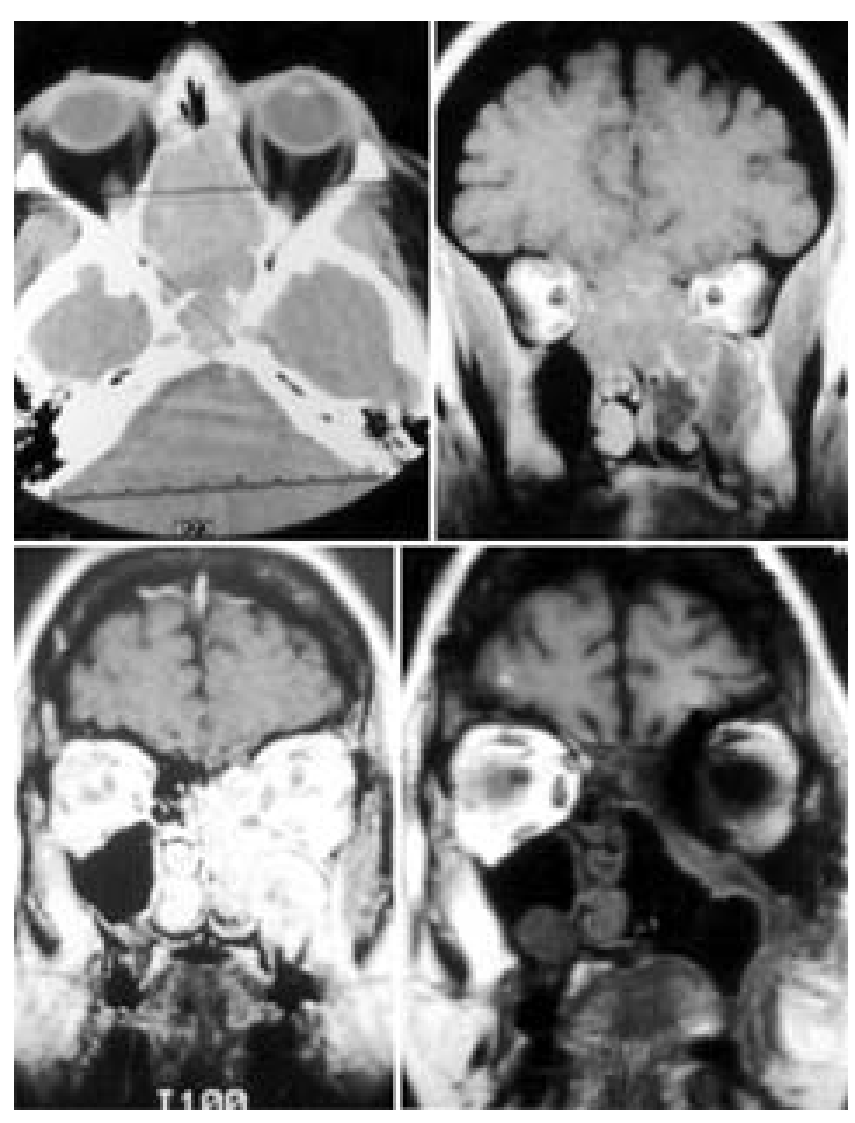

Fig. 6. Neuroimaging studies. Upper Left, Upper Right, and Lower Left: Small cell ethmoid carcinomas are managed by administering a 20-Gy dose of radiation preoperatively following aggressive resection. Lower Right: Results after excision and radiotherapy. With this paradigm long-term survival is possible.

The patient is positioned supine in a Mayfield head holder with the neck slightly flexed and the vertex up. One of three variations of the bicoronal incision can be used (Fig. 7). Over the temporalis muscle, the areolar tissue and the superficial fat pad are raised with the flap to preserve the frontalis and zygomatic branches of the facial nerve. Over the vertex toward the forehead, the scalp is elevated strictly as the subgaleal flap, leaving the loose connective tissue attached to the pericranium. The pericranium is preserved between both temporalis muscles.

One centimeter from the orbital edge, the pericranial flap is raised with the frontalis skin flap to expose the orbital ridge. Care must be taken to avoid injury to the supraorbital nerve. The supraorbital nerve may be freed from the supraorbital foramen by using a drill or osteotome. After the scalp is reflected anteriorly, the long vascularized pericranial flap will be raised, with care taken not to lacerate or perforate the pericranium. This graft can extend several inches behind the scalp incision.

The anteromedial portion of the temporal muscle is elevated posteriorly approximately 1 to 2 inches to expose the orbitotemporal rim. The first step in the craniotomy is a bifrontal craniotomy followed by the removal of the supraorbital rim (Fig. 8). Six burr holes are made using an 11-mm perforator or a 5-mm round burr. The initial two 


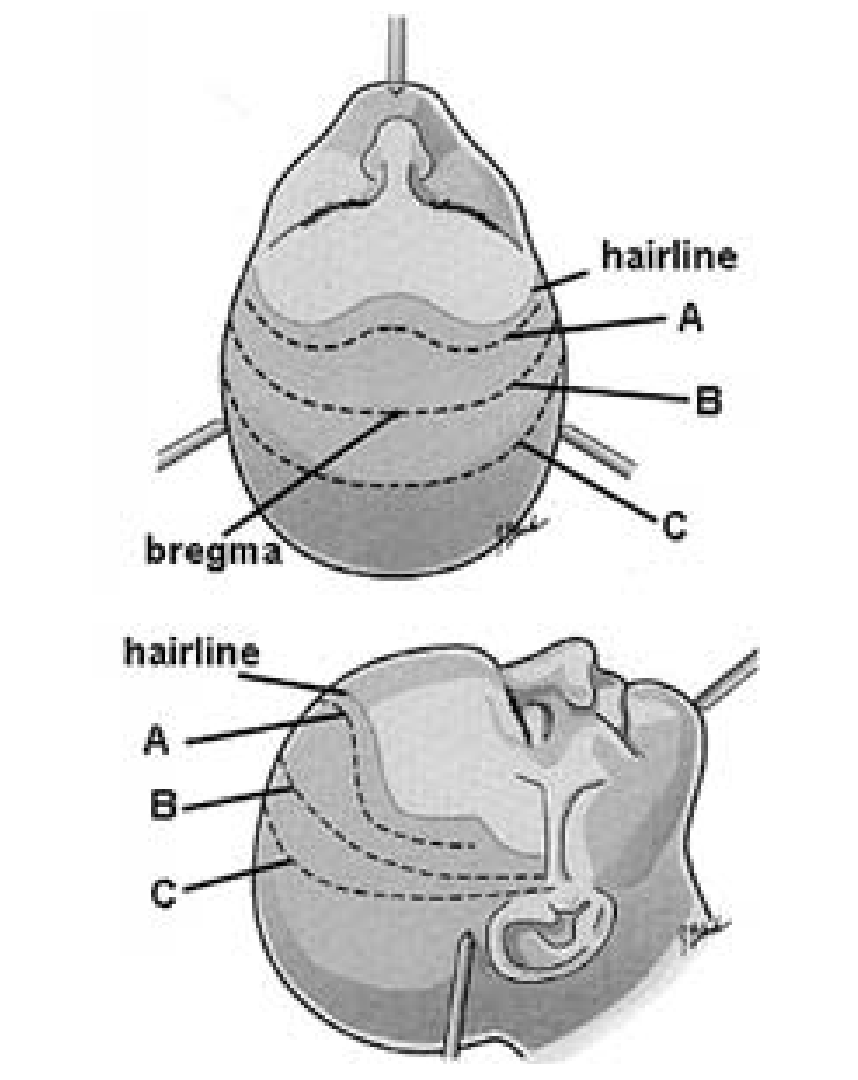

Fig. 7. Drawing demonstrating incisions for bifrontal craniotomy.

burr holes are made through the orbitotemporal region just above the pterion, and the other two burr holes are placed just above the supraorbital foramen. The last two burr holes are made in the midline: one burr hole over the sagittal sinus 1 inch anterior to the Bregma and the other just above the frontal sinus. A bifrontal osteoplastic craniotomy is then performed

Extended Bifrontal Transbasal Approach. The extended bifrontal transbasal approach adds an orbitofrontoethmoidal osteotomy to the transbasal approach described by Derome. ${ }^{21-23,28,36}$ This approach can be used to excise midline tumors involving the clivus and sphenoid sinus and extending from the base of the dorsum sellae to the foramen magnum, with some involvement of the petrous apices. Complete loss of olfaction and resultant loss of taste sensation can usually be expected after surgery via this approach. A technique for olfactory nerve preservation, as well as that of the cribriform plate, has been described..$^{72}$

After bifrontal dural elevation, a sagittal saw is used to remove the supraorbital bar. A midline osteotomy is made at the nasion, just superior to the medial canthal ligament. The periorbita is freed from the orbital roof. While protecting the periorbita with a brain spatula, the midline frontal bone and the orbital roofs are cut approximately 1 $\mathrm{cm}$ deep to the orbital ridge by using a saw or osteotomes. The lateral orbitotemporal groove is cut using a coarse diamond drill to detach the lateral orbital rim. Finally, the lateral orbital wall and the ridge are cut from the zygoma.
Following the removal of the supraorbital bar, the frontal basal dura is further separated from the anterior skull base. Using a periosteal elevator or a Fukushima dural elevator, the dura is elevated bilaterally, medial to the sphenoid ridge. The midline basal dura is dissected from the olfactory groove and from the crista galli. This olfactory portion of the dura should be sutured closed in a watertight fashion to prevent a CSF leak. It may be necessary to use a small tissue graft in patients in whom the dura is thin over the ethmoids.

The orbital roof is removed using a rongeur or Kerrison punch. The optic canal may be unroofed if the surgery is to extend to the posterior edge of the anterior fossa or if there is involvement of the anterior clinoid process. The diamond drill must be constantly cooled to avoid overheating the optic nerves. The medial orbital wall may also be resected. The key element of the frontal transbasal approach is the removal of the ethmoid and sphenoid sinuses. Once this is done, the clivus, sella floor, carotid groove, posterior pharyngeal mucosa, nasal septum, and the superior turbinates are visualized (Fig. 9).

Combined Transbasal Transcavernous Approach. In cases of cavernous sinus involvement, the transbasal approach can be combined with a transcavernous approach. This involves addition of an orbitozygomatic osteotomy. The anterior clinoid process is removed extradurally. ${ }^{25}$ The tuberculum sellae and the planum sphenoidale can be removed using a diamond burr to open widely the sphenoid sinus and the ethmoid sinus. Drilling may continue anteriorly in the midline to open the ethmoid sinus after removing the posterior cribriform plate. After removal of the anterior clinoid process, the anterior bend of the $\mathrm{C}_{3}$ segment of the ICA can be observed. The contralateral $\mathrm{CA}^{3}$ can be observed within the sphenoid sinus. Using diamond burrs, the lateral wall of the superior orbital fissure can is removed. We perform the extradural temporopolar approach to free the cavernous sinus. The dura propria of the anterior medial temporal pole is elevated from the true cavernous membrane. This dissection begins by cutting the dura in the superior few millimeters of the superior orbital fissure. The dissection is carried down to the V2 segment. The dura propria is raised from V2 segment and the adjacent gasserian ganglia. With continuous retractor pressure on the temporal lobe, the dura continues to separate toward the petrous ridge. Dural elevation medially is limited by the tentorial edge. The posterior limit will be the V3 branch of the trigeminal nerve as it exits the ganglion. The oculomotor, trochlear, and trigeminal nerve branches (V1 and V2) can be seen through the thin veil of the true cavernous membrane. The dura is opened and the anterior proximal 1 to $2 \mathrm{~cm}$ of the sylvian fissure arachnoid is split using sharp dissection.

Once the anteromedial and -lateral cavernous sinus area is exposed, attention is focused on exposing the posterior cavernous sinus region. The dura is elevated from the subtemporal middle fossa to the point where it is tethered by its attachment to the foramen ovale. The middle meningeal artery and its accompanying vein are coagulated and divided to allow full dural elevation from the middle fossa. Venous hemorrhage deriving from the middle fossa over the trigeminal nerve is controlled using surgicel. Coagulation of these veins, which communicate with the 


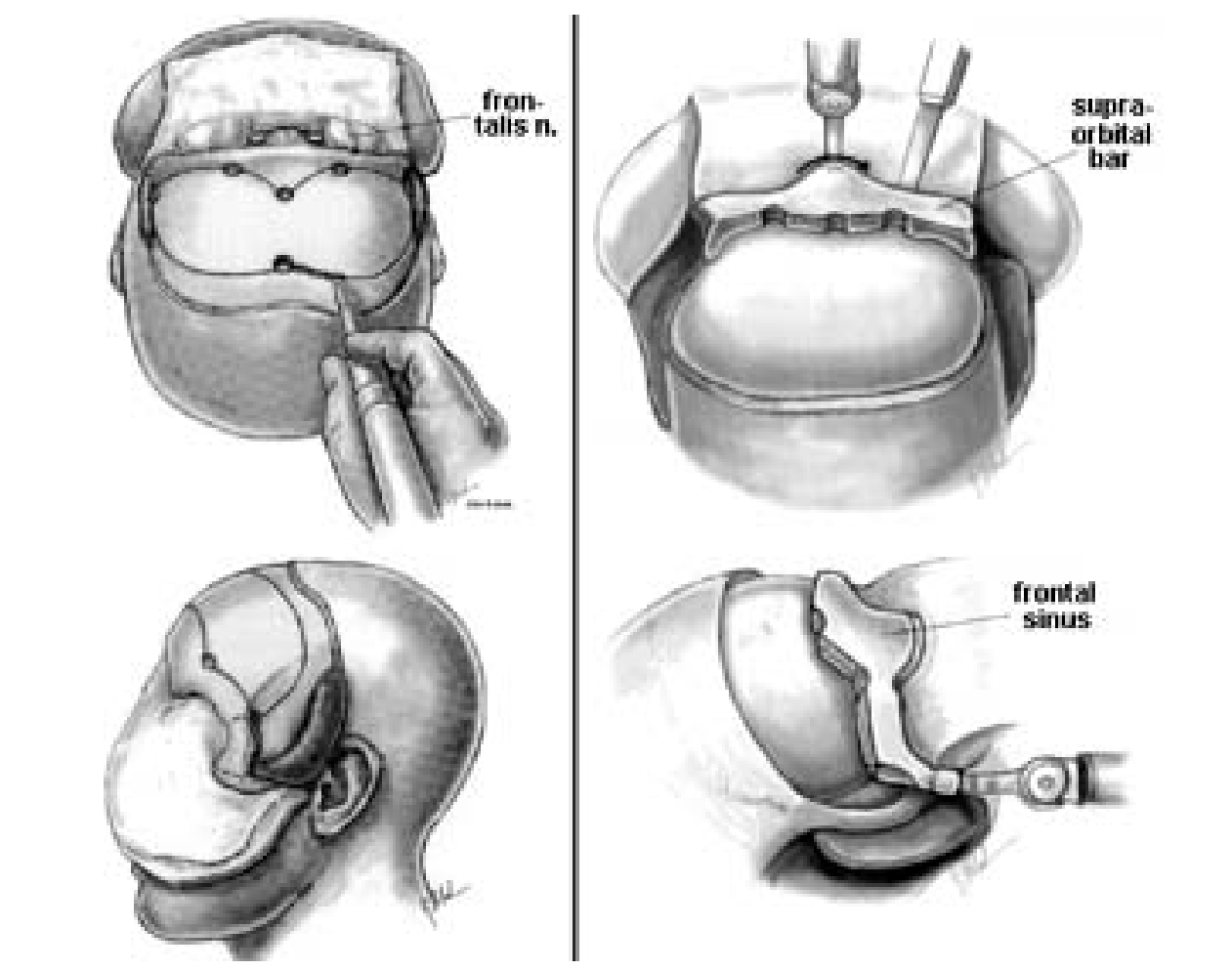

Fig. 8. Drawings. Left: Bifrontal craniotomy. Right: Removal of the supraorbital bar. $\mathrm{n}=$ nerve.

pterygoid venous plexus, will result in facial dysesthesias. The entire subtemporal middle fossa floor is shaved flat using a coarse diamond to obtain optimal visualization. The dura is elevated from the middle fossa to identify the arcuate eminence, the geniculate ganglion, and the greater superficial petrosal nerve. The foramen ovale is totally unroofed to expose the peripheral branches of V3 as it passes into the infratemporal area. This dissection is necessary to mobilize V3 and to elevate the gasserian ganglion to achieve anterior translocation of the trigeminal complex. The intrapetrous ICA is exposed by removing the bone over the posterolateral (Glasscock) triangle. With anterior translocation of the posterior border of V3, the "rhomboid area" can be identified. This is delineated by the greater superficial petrosal nerve, geniculate ganglion, arcuate eminence, the petrous ridge, and the posterior edge of V3. The petrous apex beneath the rhomboid can be safely removed medial to the $\mathrm{C}_{6}$ petrous $\mathrm{CA}$ and medial to the cochlea-geniculate ganglion complex and anterior to the arcuate eminence. This will expose the internal auditory canal, the posterior fossa dura, and the clivus.

The dural opening is continued laterally. The dura remains tethered at the fibrous dural rings that encase the $\mathrm{CA}$ and the cranial nerves. The external ring around the $\mathrm{CA}$ is cut, freeing that structure. The falciform ligament is cut, freeing the optic nerve. The tentorial edge is composed of attachments to the petrous tip, as well as the anterior and the posterior clinoid processes. The fibrous ring over the oculomotor nerve as it passes through the porus oculomotorius is also opened. The dura over the trochlear nerve is opened. If necessary the posterior clinoid process and the dorsum sellae can be removed using a diamond drill. Dissection is accomplished by drilling to the posterior clinoid process and the dorsum sellae. The cavernous sinus can be entered via one of the entry corridors initially depicted by Parkinson ${ }^{51}$ and subsequently summarized in the scheme proposed by Fukushima and Day. ${ }^{28}$

Reconstruction of the Anterior Skull Base and Closure. The supraorbital bar is replaced and fixed in place by using a plating system. The vascularized pericranial graft is laid over the supraorbital bar to the clivus. The edge of the pericranial flap is sutured to the posterior pharyngeal soft tissue, tuberculum sellae, and orbital fascia. The frontal basal dead space is filled with a free fat graft harvested from the abdomen. A watertight dural closure is needed. A microplate is used to replace the frontal bone flap. A lumbar drain is placed for 24 hours postoperatively to minimize the risk of postoperative CSF leakage.

Transbasal-Transfacial Approach. The transbasal approach can be combined with the transfacial approach for complete resection of anterior fossa malignancies that are contiguous with paranasal sinuses. Variations of the transfacial approach include the lateral rhinotomy and midfacial degloving. ${ }^{64}$

The lateral rhinotomy incision is made on the side of greater tumor involvement. The incision begins medial to the medial eyebrow, extended along the nasofacial groove and around the alar rim into the nasal vestibule. If palatal resection is necessary, the incision can be extended to split the lip in the midline.

A lateral osteotomy is made through the frontal process of the maxilla. Care is taken not to injure the nasolacrimal duct or the ligament of the medial canthus. Extension of the osteotomy across the roof of the nose allows reflection 


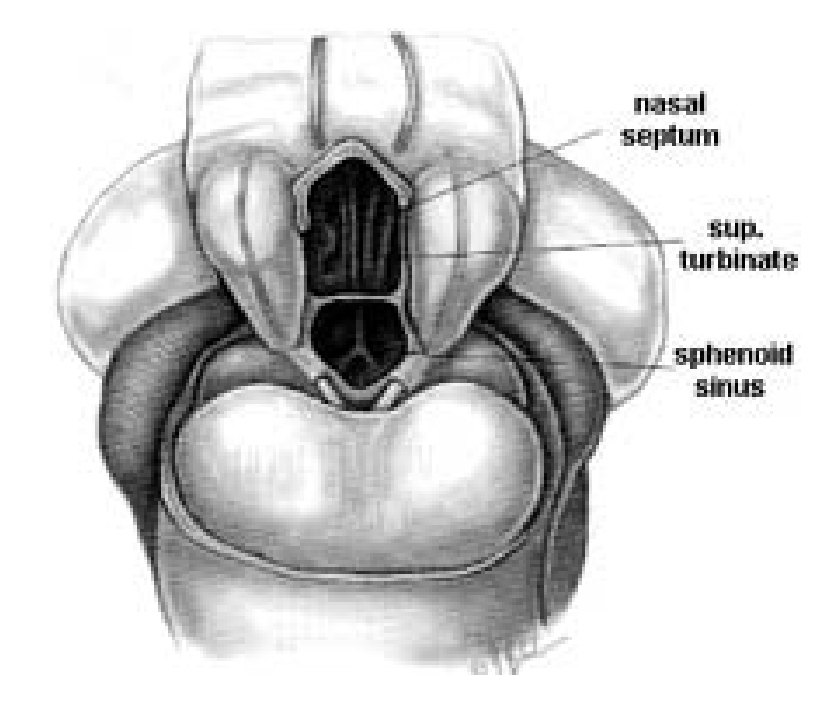

Fig. 9. View following extensive transbasal approach. sup $=$ superior.

of the nasal skeleton and overlying soft tissue to the contralateral side. The osseous nasal septum and posterior septal cartilage are separated posteriorly from the nasal bones and external nasal structure. The lacrimal duct is transected. The periorbita is elevated from the medial and inferior surfaces of the orbit, the lamina papyracea, and maxilla.

Osteotomies are created through the ipsilateral inferior meatus, medial orbital floor, and the frontoethmoid suture anterior to the optic foramen. Following the osteotomies, the tumor can be resected en bloc via the transcranial and transfacial openings.

In the midfacial degloving technique the midfacial soft tissues are reflected superiorly. Bilateral exposure of the ethmoid and maxillary area is obtained. To free the midface soft tissue, bilateral sublabial incisions, intranasal transfixation incision, bilateral intercartilaginous incisions between the upper and lower cartilages, and bilateral piriform aperture incisions extending to the vestibule of the nose are made. Following elevation of the soft tissue, Penrose drains are inserted into both nares and used to retract the midfacial soft tissue superiorly to the level of the glabella and orbits. Osteotomies are performed as previously described via the lateral rhinotomy approach.

The pericranial graft is used to provide a vascularized surface. The nasal tip is returned to its normal position. The columellar, intercartilaginous, and sublabial incisions are closed using absorbable sutures. A nasal splint is placed over the nasal dorsum.

\section{Complication Avoidance}

Both CSF leakage and meningitis are potential complications that can be minimized by obtaining a watertight dural closure. A vascularized pericranial graft to exclude the cranialized frontal sinus is critical. Significant wound complications are rare. Cranial nerve deficits may occur, but with meticulous microsurgical technique these too can be avoided.

\section{References}

1. Appelblatt $\mathrm{NH}, \mathrm{McClatchey} \mathrm{KD}$ : Olfactory neuroblastoma: a retrospective clinicopathologic study. Head Neck Surg 5: 108-113, 1982

2. Austin-Seymour M, Munzenrider J, Goitein M, et al: Fractionated proton radiation therapy of chordoma and low-grade chondrosarcoma of the base of the skull. J Neurosurg 70: 13-17, 1989

3. Barnes L, Kapadia SB: The biology and pathology of selected skull base tumors. J Neurooncol 20:213-240, 1994

4. Berson AM, Castro JR, Petti P, et al: Charged particle irradiation of chordoma and chondrosarcoma of the base of skull and cervical spine: the Lawrence Berkeley Laboratory experience. Int J Radiat Oncol Biol Phys 15:559-565, 1988

5. Bourgouin PM, Tampieri D, Robitaille Y, et al: Low-grade myxoid chondrosarcoma of the base of the skull: CT, MR, and histopathology. J Comput Assist Tomogr 16:268-273, 1992

6. Brooks JJ, LiVolsi VA, Trojanowski JQ: Does chondroid chordoma exist? Acta Neuropathol 72:229-235, 1987

7. Browne JD: The midfacial degloving procedure for nasal, sinus, and nasopharyngeal tumors. Otolaryngol Clin North Am 34: 1095-1104, 2001

8. Burger PC, Sheithauer BW: Tumors of the Central Nervous System. Washington, DC: Armed Forces Institute of Pathology, 1994, 259-281

9. Cantu G, Mattavelli F, Salvatori P, et al: [Combined transfacial and infratemporal approaches for T3-T4 malignant maxillary tumors.] Acta Otorhinolaryngologica Ital 15:345-354, 1995

10. Casson PR, Bonanno PC, Converse JM: The midface degloving procedure. Plast Reconstr Surg 53:102-103, 1974

11. Chambers PW, Schwinn CP: Chordoma. A clinicopathologic study of metastasis. Am J Clin Pathol 72:765-776, 1979

12. Choi KN, Rotman M, Aziz H, et al: Concomitant infusion cisplatin and hyperfractionated radiotherapy for locally advanced nasopharyngeal and paranasal sinus tumors. Int J Radiat Oncol Biol Phys 39:823-829, 1997

13. Chow WH, McLaughlin JK, Hrubec Z, et al: Tobacco use and nasopharyngeal carcinoma in a cohort of US veterans. Int J Cancer 55:538-540, 1993

14. Colli B, Al-Mefty O: Chordomas of the craniocervical junction: follow-up review and prognostic factors. J Neurosurg 95: 933-943, 2001

15. Collins JM: Pharmacologic rationale for regional drug delivery. J Clin Oncol 2:498-504, 1984

16. Conley J, Price JC: Sublabial approach to the nasal and nasopharyngeal cavities. Am J Surg 138:615-618, 1979

17. Cummings BJ, Hodson DI, Bush RS: Chordoma: the results of megavoltage radiation therapy. Int J Radiat Oncol Biol Phys 9:633-642, 1983

18. Cvitkovic E, Bachouchi M, Armand JP: Nasopharyngeal carcinoma. Biology, natural history, and therapeutic implications. Hematol Oncol Clin North Am 5:821-838, 1991

19. Dahlin DC, Unni KK: Bone Tumors: General Aspects and Data on 8542 Cases, ed 4. Springfield, IL: Charles Thomas, 1986

20. Dandy WE: Orbital Tumors: Results Following The Transcranial Operative Attack. New York: O Piest, 1941

21. Derome P: [Spheno-ethmoidal tumors. Possibilities for exeresis and surgical repair.] Neurochirurgie 18 (Suppl 1):1-164, 1972

22. Derome PJ, Tessier P: Craniofacial reconstruction in patients with craniofacial malformations: the neurosurgical approach. Clin Neurosurg 24:642-652, 1977

23. Derome PJ, Viscot A, Monteil JP, et al: Management of cranial chordomas, in Sekhar LN, Schramm VL Jr (eds): Tumors of the cranial base: diagnosis and treatment. Mt. Kisco, NY: Futura, 1987, pp 607-622 
24. Diaz EM Jr, Kies MS: Chemotherapy for skull base cancers. Otolaryngol Clin North Am 34:1079-1085, 2001

25. Dolenc V: Direct microsurgical repair of intracavernous vascular lesions. J Neurosurg 58:824-831, 1983

26. Effert P, Mcoy R, Abdel-Hamid M, et al: Alterations of the p53 gene in nasopharyngeal carcinoma. J Virol 66:3768-3775, 1992

27. Frazier $\mathrm{CH}$ : An approach to the hypophysis through the anterior cranial fossa. Ann Surg 57:145-150, 1913

28. Fukushima T, Day JD: Manual of Skull Base Dissection. Pittsburgh: AF Neuro Video, 1996, pp 9-29

29. Gay E, Sekhar LN, Rubinstein E, et al: Chordomas and chondrosarcomas of the cranial base: results and follow-up of 60 patients. Neurosurgery 36:887-897, 1995

30. Grunberg SM: Role of antiprogestational therapy for meningiomas. Hum Reprod (Supp 1) 9:202-207, 1994

31. Grunberg SM: The role of progesterone receptors in meningioma, in Muggia FM (ed): New Drugs, Concepts and Results in Cancer Chemotherapy. Boston: Kluwer Academic Publishers, 1991, pp 127-137

32. Grunberg SM, Weiss MH, Spitz IM, et al: Treatment of unresectable meningiomas with the antiprogesterone agent mifepristone. J Neurosurg 74:861-866, 1991

33. Haddad G, Al-Mefty O: Meningiomas: an overview, in Wilkins RH, Rengachary SS (eds): Neurosurgery, ed 2. New York: McGraw-Hill, 1996, Vol 1, pp 833-841

34. Heffelfinger MJ, Dahlin C, MacCarty CS, et al: Chordomas and cartilaginous tumors at the skull base. Cancer 32:410-420, 1973

35. Ho HC, Ng MH, Kwan HC, et al: Epstein-Barr-virus-specific IgA and IgG serum antibodies in nasopharyngeal carcinoma. Br J Cancer 34:655-660, 1976

36. Jackson IT, Hide TA: A systematic approach to tumors of the base of the skull. J Maxillofac Surg 10:92-98, 1982

37. Johns ME, Winn HR, McLean WC, et al: Pericranial flap for the closure of defects of craniofacial resection. Laryngoscope 91: 952-959, 1981

38. Ketcham AS, Hoye RC, Van Buren JM, et al: Complications of intracranial facial resection for tumors of the paranasal sinuses. Am J Surg 112:591-596, 1966

39. Ketter R, Henn W, Niedermayer I, et al: Predictive value of progression-associated chromosomal aberrations for the prognosis of meningiomas: a retrospective study of 198 cases. J Neurosurg 95:601-607, 2001

40. Kingston JE, McElwain TJ, Malpas JS: Childhood rhabdomyosarcoma: experience of the Children's Solid Tumour Group. Br J Cancer 48:195-207, 1983

41. Kleihues P, Cavenee WK: Pathology and Genetics of Tumours of the Nervous System. Lyon, IARC Press, 2000

42. Lang J: Anterior cranial base anatomy, in Sekhar LN, Schramm VL Jr (eds): Tumors of the Cranial Base: Diagnosis and Treatment. Mt. Kisco, NY: Futura, 1987, pp 247-264

43. Lee YY, Dimery IW, Van Tassel P, et al: Superselective intraarterial chemotherapy of advanced paranasal sinus tumors. Arch Otolaryngol Head Neck Surg 115:503-511, 1989

44. Lee MM, Vokes EE, Rosen A, et al: Multimodality therapy in advanced paranasal sinus carcinoma: superior long-term results. Cancer J Sci Am 5:219-223, 1999

45. Levine PA, McLean WC, Cantrell RW: Esthesioneuroblastoma: the University of Virginia experience 1960-1985. Laryngoscope 96:742-746, 1986

46. Levine PA, Scher RL, Jane JA, et al: The craniofacial resection-eleven year experience at the University of Virginia: problems and solutions. Otolaryngol Head Neck Surg 101: 665-669, 1989

47. Lo KW, Huang DP, Lau KM: p16 gene alterations in nasopharyngeal carcinoma. Cancer Res 15:2039-2043, 1995

48. Lu QL, Elia G, Lucas S, et al: Bcl-2 proto-oncogene expression in Epstein-Barr-virus-associated nasopharyngeal carcinoma. Int J Cancer 53:29-35, 1993

49. Mehta S, Verma A, Mann SB, et al: Rhabdomyosarcoma of head and neck-an analysis of 24 cases. Indian J Cancer 33: $37-42,1996$

50. Osguthorpe JD, Patel S: Craniofacial approaches to tumors of the anterior skull base. Otolaryngol Clin North Am 34: 1123-1142, 2001

51. Parkinson D: Surgical anatomy of the lateral sellar compartment (cavernous sinus). Clin Neurosurg 36:219-239, 1990

52. Paulino AC, Simon JH, Zhen W, et al: Long-term effects in children treated with radiotherapy for head and neck rahbdomyosacroma. Int J Radiat Oncol Biol Phys 48:1489-1495, 2000

53. Perez-Ordonez B, Huvos AG: Nonsquamous lesions of nasal cavity, paranasal sinuses, and nasopharynx, in Gnepp DR (ed): Diagnostic Surgical Pathology of the Head and Neck. Philadelphia: WB Saunders, 2001, pp 79-140

54. Polin RS, Sheehan JP, Chenelle AG, et al: The role of preoperative adjuvant treatment in the management of esthesioneuroblastoma: the University of Virginia experience. Neurosurgery 42:1029-1037, 1998

55. Price JC: The midfacial degloving approach to the central skullbase. Entechnology 65:174-180, 1986

56. Raffel C, Wright DC, Gutin PH, et al: Cranial chordomas: clinical presentation and results of operative and radiation therapy in twenty-six patients. Neurosurgery 17:703-710, 1985

57. Raney RB, Amar L, Vassilopoulou-Sellin R, et al: Late complications of therapy in 213 children with localized, nonorbital soft-tissue sarcoma of the head and neck: a descriptive report from the Intergroup Rhabdomyosarcoma Studies (IRS)-II and III. IRS Group of the Children's Cancer Group and the Pediatric Oncology Group. Med Pediatr Oncol 33:362-371, 1999

58. Raveh J, Turk JB, Ladrach K, et al: Extended anterior subcranial approach for skull base tumors: long-term results. J Neurosurg 82:1002-1010, 1995

59. Ray BS, McLean JM: Combined intracranial and orbital operation for retinoblastoma. Arch Ophthalmol 30:437-445, 1943

60. Rich TA, Schiller A, Suit HD, et al: Clinical and pathologic review of 48 cases of chordoma. Cancer 56:182-187, 1985

61. Richardson MS: Pathology of skull base tumors. Otolaryngol Clin North Am 34:1025-1042, 2001

62. Rosenberg AE, Nielsen GP, Keel SB, et al: Chondrosarcoma of the base of the skull: a clinicopathologic study of 200 cases with emphasis on its distinction from chordoma. Am J Surg Pathol 23:1370-1378, 1999

63. Rupa V, Rajshekhar V, Bhanu TS, et al: Primary chondroid chordoma of the base of the petrous temporal bone. J Laryngol Otol 103:771-773, 1989

64. Scher RL, Richtsmeier WJ: Craniofacial resection of anterior skull base tumors, in Wilkins RH, Rengachary SS (eds): Neurosurgery, ed 2. New York: McGraw-Hill, 1996, Vol 3, pp $1603-1610$

65. Schramm VL Jr, Myers EN, Maroon JC: Anterior skull base surgery for benign and malignant disease. Laryngoscope 89: 1077-1091, 1979

66. Sekhar LN, Gay E, Wright DC: Chordomas and chondrosarcomas of the cranial base, in Wilkins RH, Rengachary SS (eds): Neurosurgery. New York: McGraw-Hill, 1996, Vol 2, pp $1529-1543$

67. Shanmugaratnam K, Sobin LH: The World Health Organization histological classification of tumours of the upper respiratory tract and ear. A commentary on the second edition. Cancer 71: 2689-2697, 1993

68. Sheehan JM, Sheehan JP, Jane JA Sr, et al: Chemotherapy for esthesioneuroblastomas. Neurosurg Clin N Am 11:693-701, 2000

69. Simpson D: The recurrence of intracranial meningiomas after 
surgical treatment. J Neurol Neurosurg Psychiatry 20:22-39, 1957

70. Skinner DW, Van Hasselt CA, Tsao SY: Nasopharyngeal carcinoma: modes of presentation. Ann Otol Rhinol Laryngol 100:544-551, 1991

71. Smith RR, Klopp CT, Williams JM: Surgical treatment of cancer of the frontal sinus and adjacent areas. Cancer 7:991-994, 1954

72. Spetzler RF, Herman JM, Beals S, et al: Preservation of olfaction in anterior craniofacial approaches. J Neurosurg 79: 48-52, 1993

73. Spoden JE, Bumstead RM, Warner ED: Chondroid chordoma. Case report and literature review. Ann Otol Rhinol Laryngol 89:279-285, 1980

74. Stout AP: Rhabdomyosarcoma of the skeletal muscles. Ann Surg 123:447-472, 1946

75. Sturton SD, Wen HL, Sturton OG: Etiology of cancer of the nasopharynx. Cancer 19:1666-1669, 1966

76. Tessier P, Guiot G, Derome P: Orbital hypertelorism. II. Definite treatment of orbital hypertelorism (OR.H.) by craniofacial or by extracranial osteotomies. Scand J Plast Reconstr Surg 7: 39-58, 1973

77. Todo T, Adams EF, Fahlbusc h R: Inhibitory effect of trapidil on human meningioma cell proliferation via interruption of autocrine growth stimulation. J Neurosurg 78:463-469, 1993
78. Tsai ST, Jin YT, Su IJ: Expression of EBER1 in primary and metastatic nasopharyngeal carcinoma tissues using in situ hybridization: A correlation with WHO histologic subtypes. Cancer 77:231-236, 1996

79. Van Buren JM, Ommaya AK, Ketcham AS: Ten years' experience with radical combined craniofacial resection of malignant tumors of the paranasal sinuses. J Neurosurg 28:341-350, 1968

80. Vasef MA, Ferlito A, Weiss LM: Nasopharyngeal carcinoma, with emphasis on its relationship to Epstein-Barr virus. Ann Otol Rhinol Laryngol 106:348-356, 1997

81. World Health Organization: WHO Handbook for Reporting Results of Cancer Treatment. Geneva: World Health Organization, 1979

82. Zheng YM, Tuppin P, Hubert A, et al: Environmental and dietary risk factors for nasopharyngeal carcinoma: a case-control study in Zangwu Country, Guangxi, China. Br J Cancer 69: 508-514, 1994

Manuscript received May 14, 2002.

Accepted in final form September 9, 2002.

Address reprint requests to: Takanori Fukushima, M.D., D.M. Sc., Carolina Neuroscience Institute, 4030 Wake Forest Road, Suite 115, Raleigh, North Carolina 27609. 